\title{
Lei Maria da Penha: do protagonismo feminista às resistências jurídicas
}

\author{
Ley Maria da Penha: del protagonismo femenino \\ a las resistencias jurídicas
}

\author{
Carmen Hein de Campos ${ }^{1}$ \\ Kelly Gianezini ${ }^{2}$
}

\begin{abstract}
Resumo
A elaboração da lei de violência doméstica e familiar contra a mulher, conhecida como Lei Maria da Penha representou uma bem sucedida intervenção feminista no campo do direito, evidenciando o feminismo como um sujeito que ocupou um lugar de fala não autorizado pelo tradicionalismo jurídico. A lei concebe a violência doméstica como um tema complexo, integral, interdisciplinar e interinstitucional, mas a aplicação dessa perspectiva vem sendo obstaculizada por resistências institucionais e teóricas originadas no sistema de justiça. Além disso, proposições legislativas que visam alterar a lei também colocam em risco a sua perspectiva feminista. Este artigo analisa os obstáculos à efetividade da Lei Maria da Penha como uma forte reação ao protagonismo do feminismo jurídico no Brasil.
\end{abstract}

Palavras-chave: feminismo jurídico; resistências; lei de violência doméstica;

\section{Resumen}

La elaboración de la ley de violencia doméstica y familiar contra la mujer, conocida como Ley Maria da Penha representó una exitosa intervención feminista en el campo del derecho, evidenciando el feminismo como un sujeto que ocupó un lugar de habla no autorizado por el tradicionalismo jurídico. La ley concibe la violencia doméstica como un tema complejo, integral, interdisciplinario e interinstitucional, pero la aplicación de esa perspectiva viene siendo obstaculizada por resistencias institucionales y teóricas originadas en el sistema de justicia. Además, las proposiciones legislativas que apuntan a cambiar la ley también ponen en riesgo su perspectiva feminista. Este artículo analiza los obstáculos a la efectividad de la Ley Maria da Penha como una fuerte reacción al protagonismo del feminismo jurídico en Brasil.

Palabras clave: feminismo jurídico; resistencias; ley de violencia doméstica

\footnotetext{
${ }^{1}$ Doutora em Ciências Criminais, PUCRS. Docente Permanente do Programa de Pós-graduação (mestrado) em Direito do Centro Universitário Ritter dos Reis (UNIRITTER/RS). E-mail para contato: charmcampos@gmail.com

2 Doutora em Educação, UFRGS. Docente Permanente do Programa de Pós-graduação (mestrado e doutorado) em Desenvolvimento Socioeconômico da Universidade do Extremo Sul Catarinense (UNESC). Endereço: Av. Universitária, 1105, sala 14 do Bloco da Biblioteca, Bairro Universitário, CEP: 88806-000, Criciúma - SC Brasil. E-mail para contato: kellygianezini@gmail.com
} 


\section{INTRODUÇÃO}

A lei $n^{\circ} 11.340 / 2006$ (Lei Maria da Penha) é a culminância de um protagonismo feminista no campo da violência doméstica que começou na década de 1970 no Brasil. Sem dúvida, o tema da violência contra as mulheres, especialmente a praticada por parceiros íntimos, ganhou em visibilidade e pesquisas acadêmicas. Embora o campo investigativo tenha também se iniciado nos anos setenta, será a partir dos anos noventa que se consolida. No entanto, a criação da Lei Maria da Penha (LMP) impulsionou a realização de novos estudos e um aumento significativo de produções teóricas feministas (CAMPOS, SEVERI, 2018).

A percepção social da violência doméstica também mudou e certamente a LMP tem um papel decisivo. Pesquisas indicam que $98 \%$ da população brasileira já ouviu falar da Lei Maria da Penha e apenas $9 \%$ dos entrevistados acredita que bater na parceira não deveria ser crime (AGÊNCIA PATRICIA GALVÃO, 2013). Entretanto, como pesquisas também demonstram (IPEA/FBSP, 2018; 2019; CNJ, 2018), a mudança na percepção social da violência doméstica e familiar não significou, ainda, sua diminuição.

No âmbito jurídico, o entendimento da violência doméstica também vem sendo alterado. Se na década de setenta havia o acolhimento da tese da "legítima defesa da honra masculina" (PIMENTEL, PANDJIARJIAN, BELLOQUE, 2006) para homens que matavam mulheres por suposto adultério, hoje tem-se como inaceitável. Da mesma forma, a aceitação jurídica da violência doméstica como um assunto privado não encontra mais abrigo doutrinário e jurisprudencial. Nesse sentido, a criação da LMP provocou uma profunda ruptura no imaginário dos juristas ou no tradicionalismo jurídico.

Ao estabelecer um tratamento integral, interdisciplinar e intersetorial, a referida Lei absorveu a perspectiva feminista da complexidade da violência doméstica e familiar e pretendeu dar respostas mais amplas para esse fenômeno. Por isso, a proposta da LMP é mais abrangente que a perspectiva penal e está fundada na prevenção, na assistência e na contenção da violência. $\mathrm{O}$ fato (crime) violência doméstica desencadeia inúmeras consequências jurídicas que, em geral, estão entrelaçadas no campo penal, civil, assistencial, dentre outros. Não obstante, essa multiplicidade de consequências decorre do mesmo evento: a violência doméstica. É exatamente por isso que a Lei em comento estabeleceu a competência civil e penal dos juizados/varas de violência doméstica e familiar contra a mulher. Essa dupla competência - frisamos - que se origina de um único fato - a violência - tem por objetivo impedir as "peregrinações" que as mulheres têm que fazer para ter o caso resolvido. Esse é um tema que 
sofre resistência por parte do poder judiciário. A incompreensão da violência doméstica, por um lado, e o tradicionalismo jurídico por outro, tem impedido que a dupla competência seja, de fato, efetivada nas varas e juizados de violência doméstica, descortinando uma resistência no interior do sistema de justiça.

A Lei em análise define a violência doméstica como uma violência baseada no gênero, conforme estabelece a Convenção Interamericana para Prevenir, Punir e Erradicar a Violência contra a Mulher (Convenção de Belém do Pará). A incompreensão sobre o conceito de gênero e por consequência, sobre a violência baseada no gênero tem sido determinante para decisões judiciais redutoras da abrangência da proteção legal. A criação de critérios definidos a partir de uma concepção equivocada sobre o gênero demonstra também a resistência do sistema de justiça.

Este artigo analisa essas resistências como uma reação do sistema de justiça à lei que cria obstáculos concretos ao acesso à justiça e à prestação jurisdicional a mulheres em situação de violência doméstica e familiar. Para tanto, o mesmo está organizado em seis seções, a saber: Na primeira demonstram-se o objetivo, a problematização e os procedimentos metodológicos. Nas partes seguintes apresenta-se consecutivamente o protagonismo do feminismo jurídico no Brasil, as resistências institucionais, as resistências teóricas e as perspectivas do parlamento. E, na última parte, encontra-se as principais conclusões.

\section{LEI MARIA DA PENHA: PROTAGONISMO DO FEMINISMO JURÍDICO NO BRASIL}

A Lei Maria da Penha - lei $n^{\circ} 11.340$, de 07 de agosto de 2006 - que cria mecanismos para coibir a violência doméstica e familiar contra a mulher ${ }^{3}$ é fruto do protagonismo feminista e de mulheres no Brasil. Esse protagonismo pode ser observado na origem e no conteúdo da própria Lei (CAMPOS, 2017a). Na origem, destacamos o processo de produção, proposição e aprovação do projeto de lei de violência doméstica, que foi pensado e elaborado por um Consórcio de Ongs feministas durante mais de dois anos (MATOS, CORTES, 2011). A iniciativa de propor uma legislação específica para violência doméstica decorreu de

\footnotetext{
${ }^{3}$ Cabe destacar que a LMP, especialmente nos termos do $\S 8^{\circ}$ o o art. 226 da Constituição Federal, da Convenção sobre a Eliminação de Todas as Formas de Discriminação contra as Mulheres e da Convenção Interamericana para Prevenir, Punir e Erradicar a Violência contra a Mulher; dispõe sobre a criação dos Juizados de Violência Doméstica e Familiar contra a Mulher; altera o Código de Processo Penal, o Código Penal e a Lei de Execução Penal; e dá outras providências.
} 
experiências de Ongs feministas com a legislação anterior (lei no 9.099/1995) que contrariava os interesses e os tratados internacionais de direitos humanos das mulheres.

Todavia, é necessário salientar que a proposição de uma legislação específica por parte dos movimentos feministas e de mulheres no Brasil é fruto de uma longa trajetória feminista no tema. Como dito anteriormente, desde os anos setenta, as feministas denunciavam o descaso judicial com o tema da violência doméstica (BARSTED, 2011), mas foi somente em 1991 que foi apresentado o primeiro anteprojeto de lei criminalizando à violência intrafamiliar (CAMPOS, 2017b). Embora não tenha sido aprovado, essa iniciativa fortaleceu o segundo anteprojeto de lei apresentado em 2004, mais de dez anos depois. Desse modo, foram necessários mais de quarenta anos de lutas feministas para que a violência doméstica fosse reconhecida como um problema político e jurídico.

O fato de o anteprojeto ter sido elaborado por Ongs feministas e não pelo parlamento ou pelo executivo, ${ }^{4}$ ainda que o parlamento tenha discutido amplamente com os movimentos de mulheres, marca essa iniciativa como orginalmente feminista e demarca um lugar de fala até então não reconhecido pelo tradicionalismo jurídico. Ou seja, o feminismo desafia os marcos teóricos sobre os quais se disputa o que pode e o que não pode ser reconhecido como um problema político ou jurídico (CAMPOS, 2011).

Mas o protagonismo feminista está também no conteúdo da lei que introduz mudanças legais e uma perspectiva complexa para o tratamento da violência doméstica, dentre as quais destacamos: a tutela penal exclusiva para as mulheres; a criação normativa da categoria violência de gênero; a redefinição da expressão vítima; a exclusão dos crimes de violência doméstica do rol dos crimes considerados de menor potencial ofensivo e suas consequências; a previsão de a companheira ser processada por violência doméstica e familiar em relações homoafetivas; a criação de medidas protetivas de urgência; a criação dos juizados especializados de VDFCM com competência civil e criminal; o tratamento integral, intersetorial e interdisciplinar da violência doméstica e familiar (CAMPOS, 2017a, p. 12).

Isto posto, a LMP introduziu profundas mudanças no procedimento, no tratamento e no julgamento da violência doméstica. Contudo, após mais de dez anos de vigência, a LMP enfrenta ainda muitas resistências, especialmente no interior do sistema de justiça.

\section{RESISTÊNCIAS INSTITUCIONAIS À LEI MARIA DA PENHA}

\footnotetext{
${ }^{4}$ Artigo elaborado por Myllena Matos e Iáris Córtes (2011) detalha todo o processo de elaboração, tramitação legislativa e aprovação.
} 
A primeira resistência que pode ser observada foi originada pelo Poder Judiciário brasileiro, por meio de juízes que atuavam com a lei dos juizados especiais criminais (lei $\mathrm{n}^{\circ}$ 9.099/1995) $)^{5}$ e que, curiosamente, participaram ativamente do processo de discussão do projeto de lei de violência doméstica (LAVIGNE, 2011). Quando a Lei Maria da Penha retirou a competência dos juizados especiais criminais para o julgamento dos crimes cometidos com violência doméstica e familiar (lei no 9.099/1995), os magistrados não aceitaram a mudança e passaram a julgar a Lei Maria da Penha como inconstitucional (LAVIGNE, 2011).

Convém enfatizar que eram três os principais argumentos para não aplicar a LMP, a saber: a) violação do princípio da igualdade; b) violação da competência dos tribunais com a criação da dupla jurisdição (civil e criminal) nos juizados especializados de violência doméstica e familiar; e, c) violação do direito do réu a uma pena mais branda face à proibição da aplicação da lei no 9.099/1995. Como consequência, inúmeras decisões judiciais contrárias à lei foram proferidas, o que levou a Advocacia Geral da União a ajuizar, em 2007, uma Ação Declaratória de Constitucionalidade (ADC 19).

De resto, muitos Tribunais não reconheciam a ação pública incondicionada aos crimes de lesão corporal (exceto os que dependem de representação da vítima), e chancelavam a aplicação da lei no 9.099/1995, expressamente proibida pela lei. Em virtude disto, a Procuradoria da República ajuizou, em 2010, uma Ação Direta de Inconstitucionalidade (ADI 4424) ${ }^{6}$ para que o Supremo Tribunal Federal (STF) desse interpretação conforme à Constituição aos artigos que eram objeto de contestação por juízes e tribunais.

Em 2012, o Supremo Tribunal Federal julgou, conjuntamente, a ADC 19 e a ADI 4424 e considerou constitucional todos os artigos da Lei Maria da Penha. Assim, a proteção específica da mulher não violava o princípio da igualdade; os tribunais podiam (e deviam) criar varas com competência civil e criminal para o julgamento dos crimes decorrentes de violência

\footnotetext{
${ }^{5}$ A lei $\mathrm{n}^{\circ}$ 9.099, de 26 de setembro de 1995, que dispôs sobre os juizados cíveis e criminais, passou a considerar os crimes de lesão corporal leve e de ameaça como delitos de menor potencial ofensivo. Como consequência, esses crimes, quando cometidos no âmbito doméstico passaram também a ser julgados pela nova lei. Para saber mais ver Campos (1998; 2008).

${ }^{6}$ A ADI pediu que o STF desse interpretação conforme à Constituição aos artigos 12, 16 e 41 da LMP. Por esta razão é impreterível destaca-los, a seguir: Art. 12. Em todos os casos de violência doméstica e familiar contra a mulher, feito o registro da ocorrência, deverá a autoridade policial adotar, de imediato, os seguintes procedimentos, sem prejuízo daqueles previstos no Código de Processo Penal: I- ouvir a ofendida, lavrar o boletim de ocorrência e tomar a representação a termo, se apresentada; [...]. Art. 16. Nas ações penais públicas condicionadas à representação da ofendida de que trata esta Lei, só será admitida a renúncia à representação perante o juiz, em audiência especialmente designada com tal finalidade, antes do recebimento da denúncia e ouvido o Ministério Público. [...] Art. 41. Aos crimes praticados com violência doméstica e familiar contra a mulher, independentemente da pena prevista, não se aplica a Lei n 9.099, de 26 de setembro de 1995.
} 
doméstica e familiar; a não aplicação dos institutos previstos na lei no 9.099/1995 (conciliação, transação penal e suspensão condicional do processo) não deviam ser aplicados aos casos de violência doméstica e familiar; o crime de lesão corporal é crime de ação pública incondicionada. Enfim, todos os argumentos jurídicos contrários à LMP foram julgados improcedentes pelo STF.

Ainda assim, a resistência continuou e, mesmo após o julgamento pelo STF, membros do Ministério Público (MP) continuaram a propor a suspensão condicional do processo, até mesmo após a edição da Súmula 536 do Superior Tribunal de Justiça ${ }^{7}$ e com a anuência do poder judiciário. ${ }^{8}$ Observa-se, então, que a persistência de decisões judiciais que contrariam o entendimento do STF e do Superior Tribunal de Justiça (STJ) constituem-se em notórias resistências à Lei Maria da Penha.

Para além da continuidade da aplicação da suspensão condicional do processo, as resistências também se dirigem às medidas protetivas (MPUs), instituto central da lei. As MPus foram criadas como um mecanismo rápido e de fácil acesso objetivando uma proteção imediata. Previstas nos artigos 18 a 24 da LMP são de dois tipos: as que obrigam o agressor (art. 22) e de proteção à ofendida (art. 23), podendo ser requeridas pela ofendida ou pelo Ministério Público (art. 19) independentemente do registro do boletim de ocorrência, de testemunhas ou qualquer outro meio de prova. Quando solicitadas com o registro de ocorrência, a autoridade policial deve remeter o pedido dentro de $48 \mathrm{~h}$ em expediente apartado (art. 12) e o(a) juiz(a) deve analisar o pedido também em 48 h após o recebimento (art. 18).

Conquanto, uma das formas de burlar a concessão imediata da medida protetiva é fazer exigências não previstas na lei. Nessa direção, muitos magistrados passaram a exigir, para a concessão de medidas protetivas de urgência, provas testemunhais ou materiais para configuração dos crimes. Essas exigências têm inviabilizado a concessão das medidas protetivas no prazo legal de 48horas previsto na lei. É o que demonstra a pesquisa realizada no Distrito Federal por Diniz e Gumieri (2016), entre 2006 e 2012, em que 48\% dos casos tiveram as medidas negadas por falta de informações para análise dos requerimentos. Para as autoras, a

\footnotetext{
${ }^{7}$ STJ - Súmula 536 - A suspensão condicional do processo e a transação penal não se aplicam na hipótese de delitos sujeitos ao rito da Lei Maria da Penha. Disponível em: http://www.stj.jus.br/SCON/sumulas/toc.jsp?livre=SUMULA+536\&b=SUMU\&thesaurus=JURIDICO\&p=true . Acesso em: 29 mar. 2019.

${ }^{8}$ Na Reclamação 27.262, contra a decisão VII Juizado da Violência Doméstica e Familiar contra a Mulher da Comarca do Rio de Janeiro, Regional Barra da Tijuca, o ministro relator Edson Fachin em 25 maio de 2018, entendeu que não se aplica o instituto da suspensão condicional do processo aos crimes cometidos com violência doméstica, conforme decisão do STF na ADC 19 e na ADI 4424.
} 
postura do Poder Judiciário é protelatória, pois "ignora o caráter urgente da medida e sobrecarrega as vítimas com um ônus argumentativo e probatório” (DINIZ, GUMIERI, 2016, p. 215).

Outro elemento que tem sido observado para denegar a medida é o descrédito na palavra da vítima. Sabe-se que a violência doméstica geralmente ocorre sem testemunhas (LAVIGNE, PERLINGEIRO, 2011) e por isso, a palavra da vítima não pode ser mitigada. A desconfiança sobre o relato da vítima provoca uma inversão do ônus probatório, o que não é admitido pela LMP, e desvirtua o caráter urgente da medida e a centralidade conferida à mulher e não ao réu (CAMPOS, 2017a). É importante revelar que um em cada quatro pedidos é indeferido sem justificativa (DINIZ, GUMIERI 2016) ou por não possuir as provas ou testemunhas necessárias (PASINATO et al., 2016).

Mais recentemente, medidas administrativas do Conselho Nacional de Justiça ${ }^{9}$ (CNJ), órgão vinculado ao STF, indicam resistências à aplicação da Lei Maria da Penha. No período em que o CNJ foi presidido pela Ministra Carmen Lúcia (2016-2018), houve apoio a medidas alternativas de resolução de conflitos em casos de violência doméstica. Nesse sentido, o CNJ desenvolveu a Campanha Justiça pela Paz em Casa, cujo objetivo declarado era "ampliar a efetividade da Lei Maria da Penha" ${ }^{10}$ mas que tem se resumido a mutirões para julgamento de processos. Além de tudo, a ministra incentivou a aplicação da justiça restaurativa e de constelações familiares a casos de violência doméstica e familiar. Curiosamente, foi durante a gestão da referida ministra e com sua presença em um evento realizado na Bahia em 2017, ${ }^{11}$ que houve a mudança do nome da Vara de Violência Doméstica e Familiar para "Vara da Justiça pela Paz em Casa”. Essa situação revela uma afronta sem precedentes à Lei Maria da Penha. Após inúmeras críticas, a Vara retornou ao nome previsto na Lei [Vara de Violência Doméstica e Familiar contra a Mulher]. ${ }^{12}$

Essas situações demonstram a dificuldade de inúmeros profissionais do direito de se adaptarem à nova legislação. Ao que tudo indica, a legislação deveria se adequar às perspectivas

\footnotetext{
${ }^{9} \mathrm{O}$ Conselho Nacional de Justiça visa aperfeiçoar o trabalho do sistema judiciário brasileiro, principalmente no que diz respeito ao controle e à transparência administrativa e processual. Tem como missão desenvolver políticas judiciárias que promovam a efetividade e a unidade do Poder Judiciário, orientadas para os valores de justiça e paz social.

${ }^{10}$ Documento eletrônico. Disponível em: http://www.cnj.jus.br/programas-e-acoes/lei-maria-da-penha/justicapela-paz-em-casa. Acesso em: 25 mar. 2019.

11 Documento eletrônico. Disponível em: https://www.bahianoticias.com.br/justica/noticia/57275-tj-ba-mudanome-de-varas-de-violencia-para-justica-pela-paz-em-casa.html. Acesso em: 25 mar. 2019.

${ }^{12}$ Documento eletrônico. Disponível em: https://www.bahianoticias.com.br/justica/noticia/60254-apos-criticas-tjba-muda-novamente-nome-de-vara-da-violencia-domestica.html. Acesso em: 27 mar. 2019.
} 
morais dos julgadores/as e não o contrário. Veremos a seguir as referências teóricas existentes até o momento.

\section{RESISTÊNCIAS TEÓRICAS}

Ao lado das resistências institucionais, há resistências teóricas que podem ser caracterizadas pela confusão conceitual sobre o gênero e pela criação de critérios manifestamente ilegais para a concessão das medidas protetivas. Todas elas impedem a correta aplicação da lei e criam prejuízos às mulheres que ficam sem proteção, causando uma percepção negativa sobre a lei.

Pesquisa realizada por Vanessa Ramos da Silva e Paula Pinhal de Carlos, em 2018, com 163 acórdãos do Tribunal de Justiça do Rio Grande do Sul apontou uma confusão conceitual entre sexo e gênero:

Da citada normativa legal, então, se depreende que a incidência da Lei $\mathrm{n}^{\circ}$ 11.340/06 depende de a violência ter como base a questão de gênero, ou seja, ser praticada por pessoa do sexo masculino contra pessoa do sexo feminino. E tanto se justifica na medida em que o intuito da mencionada legislação é justamente proteger e criar mecanismos para coibir a violência doméstica e familiar contra a mulher em situação de vulnerabilidade. [...] No caso concreto não há dúvidas de que os delitos em tese praticados guardam direta relação com questão de gênero. E não apenas porque praticados por homem contra mulher, mas porque no âmbito de relação familiar. (grifo nosso) (Tribunal de Justiça do Rio Grande do Sul. Conflito de Jurisdição no 70063555171 .Terceira Câmara Criminal, Relator: Sérgio Miguel Achutti Blattes. Porto Alegre, 2015a, apud Silva e Carlos, 2018).

A análise da decisão permite observar que há uma confusão conceitual entre sexo e gênero com a identificação do sujeito ativo com o sexo masculino (homem). De mais a mais, há criação de critério de inclusão/exclusão (vulnerabilidade) e a restrição da violência ao âmbito familiar.

A identificação do gênero com sexo biológico já é tema discutido na literatura feminista. Esse debate iniciou na década de 1980 quando as feministas afirmaram que o gênero não necessariamente corresponde ao sexo biológico (SCOTT, 1995; HARDING, 1993; FRASER, NICHOLSON, 1992; BUTLER, 2003). Para elas, "gênero é uma categoria engendrada para se referir ao caráter fundante da construção cultural das diferenças sexuais, a tal ponto que as definições sociais das diferenças sexuais é que são interpretadas a partir das definições culturais de gênero" (MACHADO, 2000, p. 5). Embora entrelaçados, a distinção entre sexo/gênero foi 
recentemente explicitada na Recomendação Geral 33 do Comitê CEDAW e isso é juridicamente importante considerar, uma vez que o Brasil é signatário da Convenção sobre a Eliminação de Todas as formas de Discriminação contra a Mulher (CEDAW). Conforme a Recomendação:

7. A discriminação pode ser dirigida contra as mulheres por motivo de sexo e gênero. Gênero refere-se a identidades, atributos e papéis socialmente construídos para mulheres e homens e ao significado cultural imposto pela sociedade às diferenças biológicas, que se reproduzem constantemente no sistema de justiça e suas instituições. Em virtude do artigo 5 (a) da Convenção, os Estados partes têm a obrigação de tornar visíveis e remover as barreiras sociais e culturais subjacentes, incluídos os estereótipos de gênero, que impedem as mulheres de exercer e reivindicar seus direitos e seu acesso a remédios efetivo (grifo nosso).

Consequência direta da confusão teórica entre sexo e gênero é o entendimento de que a violência de gênero deve ser necessariamente praticada por pessoa do sexo masculino contra pessoa do sexo feminino. Ao fazer essa associação mecânica, a decisão ignora o disposto na Convenção, no art. $2^{\circ}$ da LMP que garante proteção às mulheres sem discriminação ${ }^{13} \mathrm{e} o$ parágrafo único do art. $5^{\circ}$ da Lei para o qual a violência baseada no gênero independe de orientação sexual. Como consequência, cria critério de aplicabilidade não previsto em lei. Assim, ao pressupor que o agressor deverá ser sempre do sexo masculino, compreende gênero como sinônimo de sexo (SILVA, CARLOS, 2018).

Ademais, a decisão afirma que o intuito da legislação é "proteger e criar mecanismos para coibir a violência doméstica e familiar contra a mulher em situação de vulnerabilidade". Ao adicionar a vulnerabilidade como condição para a proteção legal, o Tribunal criou critério de inclusão (vulnerabilidade) e exclusão (não vulnerabilidade) não previstos em lei. Desta forma, o TJRS assenta que somente as mulheres consideradas "vulneráveis" serão protegidas pela lei. A LMP determina que se observem "as condições peculiares das mulheres em situação de violência doméstica e familiar" (art. $4^{\circ}$ ), o que significa perceber que algumas mulheres são de fato, mais vulneráveis que outras. Mas esse não é um critério de inclusão de algumas mulheres (vulneráveis) e exclusão de outras (menos vulneráveis). Trata-se de um critério a ser considerado objetivando a maior proteção, como por exemplo, para a inclusão em programas

\footnotetext{
${ }^{13}$ Art. $2^{\circ}$ - Toda mulher, independentemente de classe, raça, etnia, orientação sexual, renda, cultura, nível educacional, idade e religião, goza dos direitos fundamentais inerentes à pessoa humana, sendo-lhe asseguradas as oportunidades e facilidades para viver sem violência, preservar sua saúde física e mental e seu aperfeiçoamento moral, intelectual e social.
} 
de assistência e de proteção, na análise das condições econômicas, sociais e educacionais das mulheres para tomar a melhor decisão e para identificação de medidas que possam auxiliar no rompimento da situação de violência. Tampouco é parâmetro para exclusão de mulheres que não preencham a condição de vulnerabilidade social, econômica ou educacional.

Se a vulnerabilidade social agrava a situação de violência de muitas mulheres, a violência baseada no gênero independe da vulnerabilidade. Por essa razão há mulheres consideradas "empoderadas" ou bem sucedidas que sofrem violência doméstica, pois a violência baseada no gênero expressa uma relação de poder e não necessariamente pressupõe uma vulnerabilidade (econômica ou social). Pode-se exemplificar com alguns casos recentes.

Em 02 de fevereiro de 2012, Ana Alice Moreira de Melo procuradora federal, foi morta por seu marido, aos 35 anos de idade. ${ }^{14}$ Ana morava em um condomínio de luxo em Nova Lima, na região metropolitana de Belo Horizonte. Em 2013, Glauciane Chaves de Melo, juíza de direito, foi morta a tiros, pelo ex-companheiro, durante horário de expediente, no interior do Fórum da Comarca de Alto Taquari, em Mato Grosso. ${ }^{15}$ No dia 20 de agosto de 2017, Cláudia Zerati, juíza titular da $2^{\mathrm{a}}$ Vara do Trabalho de Franco da Rocha, foi morta pelo marido, o delegado Cristian Lanfredi, na cidade de Campinas, São Paulo que se suicidou a seguir. ${ }^{16}$ Nos três casos, as mulheres queriam separar-se de seus maridos ou companheiros e esses não aceitavam a separação. Pode-se afirmar que a vulnerabilidade social amplia os riscos para as mulheres mais pobres, negras e de baixa escolaridade, mas a violência de gênero não pode ser a ela condicionada e tampouco ser condição necessária para a proteção jurídica.

Além do que, o conceito de violência baseada no gênero não se reduz à submissão ou subordinação da mulher ao domínio masculino (dominação) como afirmado na decisão "como bem demonstrado nos autos, a lesão foi cometida pelo namorado da vítima, na ocasião em que agrediu a ofendida, o que se qualifica como violência de gênero, expressando a posição de dominação do homem e subordinação da mulher" (Tribunal de Justiça do Rio Grande do Sul. Conflito de Jurisdição no 70066827734, 2015b). Segunda Câmara Criminal. Relator: José Antônio Cidade Pitrez apud SILVA, CARLOS, 2018).

A afirmação contém uma equivocada associação do gênero à subordinação feminina e à dominação masculina. Subordinação e dominação estão associadas ao conceito de patriarcado

\footnotetext{
${ }^{14}$ Documento eletrônico. Disponível em: http://g1.globo.com/minas-gerais/noticia/2012/02/procuradora-mortaem-condominio-era-ameacada-pelo-ex-diz-pm.html. Acesso em: 29 mar. 2019.

${ }^{15}$ Documento eletrônico. Disponível em: http://g1.globo.com/mato-grosso/noticia/2013/06/juiza-e-assassinadapelo-ex-marido-dentro-de-forum-em-cidade-de-mt.html. Acesso em: 29 mar. 2019.

16 Documento eletrônico. Disponível em: https://g1.globo.com/sp/campinas-regiao/noticia/juiza-morta-pelomarido-e-enterrada-em-campinas.ghtml. Acesso em: 29 mar. 2019.
} 
como um sistema de dominação/exploração masculina e de subordinação das mulheres. $\mathrm{O}$ conceito de gênero ou de relações de gênero, como explica Lia Zannota Machado (2000) não veio para substituir o de patriarcado, mas para demonstrar que as relações entre "homens e mulheres" ou "entre os sexos" não podem ser aprisionadas nas narrativas da naturalização e da biologização das relações entre homens e mulheres".

É exatamente porque as relações hierárquicas de gênero são postas em questão que as agressões acontecem. Ao não aceitarem submeter-se a relações desiguais de gênero, a violência é utilizada como um mecanismo de controle sobre as mulheres (CAMPOS, 2017a). A pesquisa em comento identificou ainda a exigência de outros critérios para a aplicação da Lei $n^{\circ}$ 11.340/2006 tais como: a) existência de relação íntima de afeto entre agressor e vítima; b) existência de violência de gênero, direcionada à prática delitiva contra mulher; e, c) situação de vulnerabilidade, hipossuficiência e inferioridade física ou econômica da vítima em relação ao agressor.

Não identifico, na espécie, a submissão da vítima frente ao agressor em razão de gênero, ou mesmo, situação de vulnerabilidade, hipossuficiência e inferioridade física ou econômica. Além disso, eles não residem na mesma residência, e a mera relação de parentesco por afinidade não é suficiente para fazer incidir a lei especial. E a manifestação ministerial é favorável ao imputado, por óbvias razões, recomendando ser seguida. (Tribunal de Justiça do Rio Grande do Sul. Conflito de Jurisdição no 70068211424. Terceira Câmara Criminal. Relator: João Batista Marques Tovo, 2016, apud Silva e Carlos, 2018).

O acórdão em análise apresenta requisitos estranhos à legislação tais como: a) a necessidade da submissão da vítima frente ao agressor; b) a situação de vulnerabilidade, hipossuficiência e inferioridade física ou econômica da vítima; c) a necessidade de viverem na mesma residência; e, d) a insuficiência da relação de parentesco. Sem exceção, esses critérios criados pela jurisprudência são alheios à LMP. Como já argumentamos, a Lei não exige nenhuma dessas condições para que as mulheres obtenham proteção. A criação de critérios não previstos na legislação é uma violação à LMP. Agindo dessa forma, o TJRS vai além da interpretação da lei e ingressa no âmbito do legislador. Desta forma, impede o acesso à justiça por parte de mulheres que que sofrem violência doméstica ou familiar, mas que não se enquadrem nos critérios jurisprudenciais elaborados pelo Tribunal.

Nesse sentido, pode-se afirmar com as autoras que o Tribunal de Justiça do Rio Grande do Sul cria requisitos que não existem na lei, entende o termo "gênero" como sinônimo do termo "sexo", não faz diferenciação entre violência doméstica e conjugal e exige a coabitação 
para caracterizar o vínculo (SILVA, CARLOS, 2018).

Mas é importante mencionar que apesar dessas resistências, há decisões judiciais em sentido oposto, como as que têm garantido a aplicação da Lei Maria da Penha a mulheres trans. Apenas para exemplificar, mencionamos a decisão, do juiz André Luiz Nicolitt, ${ }^{17}$ da Vara de Violência Doméstica da Comarca de São Gonçalo, no Rio de Janeiro (RJ), que afirma que "enquanto o sexo que pode ser masculino ou feminino, é um conceito biológico, o gênero, também feminino e masculino, é um conceito sociológico independente do sexo" (p. 4). Ou ainda, o acórdão da $1^{\text {a }}$ Turma Criminal do Tribunal de Justiça do Distrito Federal e Territórios (TJDFT)

2. O gênero feminino decorre da liberdade de autodeterminação individual, sendo apresentado socialmente pelo nome que adota, pela forma como se comporta, se veste e se identifica como pessoa. A alteração do registro de identidade ou a cirurgia de transgenitalização são apenas opções disponíveis para que exerça de forma plena e sem constrangimentos essa liberdade de escolha. Não se trata de condicionantes para que seja considerada mulher (20171610076127 RSE).

Conclui-se que as resistências institucionais (no interior do próprio sistema de justiça) e jurídicas atuam como obstáculos à implementação da LMP. Esse déficit teórico (resistências jurídicas) demonstra também a baixa absorção dos parâmetros normativos internacionais por parte dos tribunais brasileiros. Os instrumentos internacionais de proteção dos direitos humanos expressamente mencionados na LMP (Convenção CEDAW e Convenção de Belém do Pará) devem ser utilizados como guia interpretativo e assim, contribuir para evitar imprecisão teórica e melhorar a compreensão do conceito de gênero e de violência baseada no gênero e consequentemente, a aplicação da LMP.

\section{PERSPECTIVAS DO PARLAMENTO}

Por mais de dez anos, os movimentos feministas e de mulheres em parceria com a Secretaria de Políticas para as Mulheres da Presidência da República (SPM/PR) conseguiram frear propostas de alteração da Lei Maria da Penha. O argumento era de que primeiro, a lei deveria ser plenamente aplicada, para depois, se fosse o caso, reformá-la. Essa estratégia mostrou-se exitosa, pois a primeira alteração na lei ocorreu somente em 2017 . $^{18}$

\footnotetext{
${ }^{17}$ Processo n ${ }^{\circ}$ 0018790-25.2017.8.19.0004.

${ }^{18}$ A Lei n $^{\circ} 13.505$, de 08 de novembro de 2017, acrescentou dispositivos à Lei no 11.340 , de 7 de agosto de 2006 (Lei Maria da Penha), especialmente no art. 10, para dispor sobre o direito da mulher em situação de violência Revista Juris Poiesis - Rio de Janeiro. Vol.22-n²8, 2019, pg.253- 269. ISSN 2448-0517
} 
Apesar disso, desde a sua edição, vários projetos foram propostos para alterar a LMP. A título exemplificativo, em uma rápida busca na página eletrônica da Câmara dos Deputados, ${ }^{19}$ com a expressão "Maria da Penha" foi possível encontrar, apenas em 2019, 35 projetos de lei (PL) que, de algum modo, alteram a Lei Maria da Penha. Por certo, nem todos as proposições legislativas comprometem o conteúdo da lei, mas é importante destacar a profusão de projetos que objetivam mudar a lei. Por isso, o fato de que a lei não tenha sofrido alterações em dez anos pode ser avaliado como um aspecto positivo, uma vez que durante esse período, não apenas a “ânsia" legislativa foi contida, mas foram produzidas diversas pesquisas sobre a aplicação da Lei Maria da Penha (AZEVEDO, et. al, 2016; PASINATO, 2009; PASINATO, et. al, 2016).

Entretanto, há projetos que visam alterar aspectos fundamentais da Lei, a exemplo do PL 11/2019, de autoria da deputada Joice Hasselmann (PSL/SP) que acrescenta artigo para que autoridades policiais possam aplicar medidas protetivas emergenciais às mulheres vítimas de violência doméstica. A proposta tem o mesmo conteúdo do PLC 07/2016 que foi aprovado pelo Congresso Nacional e vetado pelo então Presidente da República Michel Temer após manifestação contrária de movimentos feministas e de instituições vinculadas ao sistema de justiça. $^{20}$

O projeto de lei altera conteúdo importante da Lei Maria da Penha que é a apreciação pelo poder judiciário, da medida protetiva de urgência. A proposição foi criticada por vício de constitucionalidade e porque foi apresentada por integrantes da polícia civil sem discussão com os movimentos feministas e de mulheres, autoras do anteprojeto de lei que culminou com a elaboração e aprovação da Lei Maria da Penha.

O argumento parlamentar é de que há demora na concessão das medidas protetivas por parte do poder judiciário, com o qual concordamos e as pesquisas demonstram. Não pretendemos aqui, discutir os argumentos referentes à inconstitucionalidade da proposição legislativa. $\mathrm{O}$ que se quer é demonstrar a existência de projeto de lei que altera um aspecto relevante da lei, o que pode comprometer a efetividade da Lei Maria da Penha.

doméstica e familiar de ter atendimento policial e pericial especializado, ininterrupto e prestado, preferencialmente, por servidores do sexo feminino.

19 Documento eletrônico. Disponível em: https://www.camara.leg.br/buscaportal?contextoBusca=BuscaProposicoes\&pagina=3\&order=relevancia\&abaE specifica $=$ true $\& q=1$ ei\%20maria\%20da\%20penha. Acesso em: 29 mar. 2019.

20 Apresentaram notas contrárias à aprovação do PLC 07/2016 o Consórcio de ONGs que elaborou a Lei Maria da Penha; o Instituto Maria da Penha (IMP); a Ordem dos Advogados do Brasil (OAB); a Associação de Magistrados Brasileiros (AMB); o Conselho Nacional de Procuradores-Gerais dos Ministérios Públicos dos Estados e da União (CNPG); a Associação Nocional dos Membros do Ministério Público (CONAMP); o Colégio Nacional de Defensores Públicos Gerais (CONDEGE); o Fórum Nacional dos Juízes de Violência Doméstica e Familiar contra a Mulher (FONAVID); a Procuradoria Federal dos Direitos do Cidadão (PFDC). 
No entanto, pode-se argumentar que a perspectiva do parlamento é distinta da judicial porque objetiva tornar a legislação mais ágil e mais protetora. $\mathrm{O}$ sistema de justiça, como demonstramos, tem imposto obstáculos que dificultam o acesso à justiça e limitam a proteção das mulheres. Entretanto, entendemos que, ao invés de alterar a Lei Maria da Penha ampliando os poderes de polícia do estado, o que deveria ser feito é melhorar a prestação jurisdicional, ampliando o número de juizados especializados, criando equipes multidisciplinares, afastando alternativas jurídicas que violam a Lei Maria da Penha, vedando a inclusão de critérios que limitam o acesso à justiça e a proteção das mulheres. Ou seja, há necessidade de fiscalização do sistema de justiça em todas as suas instituições para evitar o descumprimento deliberado da lei.

\section{CONSIDERAÇÕES FINAIS}

A transformação do tratamento jurídico da violência doméstica contra mulheres demorou décadas e é fruto da persistência e do protagonismo dos movimentos feministas e de mulheres brasileiros, cujo momento máximo foi a edição da Lei Maria da Penha. As resistências no âmbito jurídico à proposta feminista de tratamento da violência contra mulheres são uma forte reação a esse protagonismo que ousou ocupar um lugar de fala até então, não autorizado.

As contestações à lei são facilmente observadas por meio de inúmeros empecilhos que as mulheres devem vencer para que lhes seja garantida proteção jurídica. Matizadas por discursos jurídicos, as resistências à implementação da LMP demonstram que o sistema de justiça não apenas não incorporou a perspectiva de gênero prevista na lei e nos tratados de direitos humanos como luta para manter seu lugar de poder. Ou seja, o discurso judicial atua fortemente como um discurso de poder oposto ao gênero e ao feminismo e interfere diretamente na vida das mulheres, causando prejuízos no acesso à justiça.

Após dez anos de vigência da lei esperava-se que as resistências diminuíssem, especialmente após o julgamento da constitucionalidade da LMP pelo STF. Entretanto, o que se verifica é que a vontade tenaz de não aplicar a Lei Maria da Penha e mesmo de fortemente confrontá-la não foi aplacada. Por sua vez, o CNJ, órgão do Poder Judiciário que deveria velar pela correta aplicação da lei tem atuado em sentido contrário, pois iniciativas que violam expressamente a LMP são incentivadas e realizadas com o seu apoio.

As resistências institucionais e teóricas à Lei Maria da Penha são uma ameaça à prevenção e erradicação da violência doméstica e familiar no Brasil e por isso deveriam ser 
contidas pelas instituições do próprio sistema de justiça. Para tanto, a perspectiva de gênero deve ser seriamente incorporada em todo o sistema de justiça, por meio do acolhimento dos instrumentos internacionais de proteção dos direitos humanos.

É inaceitável que o Brasil seja signatário há décadas desses instrumentos jurídicos e que integrantes do sistema de justiça atuem em completa dissintonia a esses instrumentos. Dar efetividade à Lei Maria da Penha começa por entender que essa legislação insere-se em uma perspectiva teórica e de luta social sobre a violência baseada no gênero fundada em pesquisas e estudos de longa data. Respeitar a normativa legal é um dever dos poderes integrantes do sistema de justiça e um direito das mulheres de garantia de proteção.

\section{AGRADECIMENTOS}

Agradecimentos especiais ao Conselho Nacional de Pesquisa (CNPq), à Coordenação de Aperfeiçoamento de Pessoal de Nível Superior (CAPES), aos Programas de Pós-graduação em Direito e em Desenvolvimento Socioeconômico pelo fomento para realizar esta pesquisa. As autoras afirmam que não há conflitos de interesse na publicização deste artigo.

\section{REFERENCIAS}

AGÊNCIA PATRÍCIA GALVÃO. Percepção da sociedade sobre violência e assassinatos de mulheres. Disponível em: https://dossies.agenciapatriciagalvao.org.br/violencia/wpcontent/uploads/2015/07/DATAPOPULAR_IPG_violenciaeassassinatos2013.pdf. Acesso em: 20 fev. 2019.

AZEVEDO, Rodrigo. G.; RIBEIRO, L. M.; RATTON, J. L.; VASCONCELLOS, Fernanda. B.; BORBA, C. G. C.; COUTO, V. A.; SILVA, C. C. Aplicação das medidas protetivas para as mulheres em situação de violência nas cidades de Porto Alegre (RS), Belo Horizonte (MG) e Recife (PE). In: PARESCHI, A. C. C.; ENGEL, C. L.; BAPTISTA, G. C. (Org.). Direitos humanos, grupos vulneráveis e segurança pública. Brasília, DF: Ministério da Justiça, 2016. (Coleção Pensando a Segurança Pública, v. 6). p. 267-302.

BARSTED, L. L. Lei Maria da Penha: uma experiência bem-sucedida de advocacy feminista. In CAMPOS, C. H. (Org.) Lei Maria da Penha comentada em uma perspectiva jurídicofeminista. Rio de Janeiro: Lumen Juris, 2011. p.13-37.

BUTLER, Judith. Problema de gênero: feminismo e subversão da identidade. Rio de Janeiro: Civilização Brasileira, 3a ed; 2010.

CAMPOS, Carmen Hein de. Criminologia e Feminismo: teoria feminista e crítica às criminologias. Rio de Janeiro: Lumen Juris, $2017 \mathrm{~b}$.

CAMPOS, Carmen Hein de. Lei Maria da Penha: necessidade de um novo giro paradigmático. Revista Brasileira de Segurança Pública. São Paulo, v. 11, n. 1, Fev/Mar 2017a, p. 10-22. 
CAMPOS, Carmen Hein de. Razão e Sensibilidade: Teoria Feminista do Direito e Lei Maria da Penha. In: CAMPOS, C. H. (Org.). Lei Maria da Penha comentada em uma perspectiva jurídico-feminista. Rio de Janeiro: Lumen Juris, 2011. p. 1-12.

CAMPOS, Carmen Hein de. SEVERI, Fabiana Cristina. Violência contra mulheres e a crítica jurídica feminista: breve análise da produção acadêmica brasileira. Revista Direito e Práxis, Rio de Janeiro, 2018.

CONSELHO NACIONAL DE JUSTIÇA. O poder judiciário na aplicação da Lei Maria da Penha. Brasília: CNJ, 2018.

DINIZ, Débora.; GUMIERI, Sinara. Implementação de medidas protetivas da Lei Maria da Penha no Distrito Federal entre 2006 e 2012. In: PARESCHI, A. C. C.; ENGEL, C. L.; BAPTISTA, G. C. (Org.). Direitos humanos, grupos vulneráveis e segurança pública. Brasília, DF: Ministério da Justiça, 2016. (Coleção Pensando a Segurança Pública, v. 6). p. 205-231.

FÓRUM BRASILEIRO DE SEGURANÇA PÚBLICA. Visível e invisível: a vitimização das mulheres no Brasil. 2a, ed. 2019. Infográfico. Disponível em:

http://www.ipea.gov.br/portal/images/stories/PDFs/relatorio_institucional/180604_atlas_da_v iolencia_2018.pdf. Acesso em: 08 mar. 2019.

FRASER, Nancy; NICHOLSON, Linda. Crítica social sin filosofia: un encuentro entre el feminismo y el postmodernismo. In NICHOLSON, Linda. Feminismo/posmodernismo (Comp). Buenos Aires: Feminaria, 1992, p.

HARDING, Sandra. Ciencia y feminismo. Espanha: Ediciones Morata, S. L.;1996.

INSTITUTO AVON; DATA POPULAR. Percepções dos homens sobre violência doméstica. São Paulo: Instituto Avon, 2014. Disponível em: www.institutoavon.org.br. Acesso em: 11 fev. 2019.

IPEA/FBSP. Atlas da violência 2018. Disponível em:

http://www.ipea.gov.br/portal/images/stories/PDFs/relatorio_institucional/180604_atlas_da_v iolencia_2018.pdf. Acesso em: 20 fev. 2019.

LAVIGNE, R. R.; PERLINGEIRO, C. Das medidas protetivas de urgência - artigos 18 a 21. In: CAMPOS, C. H. Lei Maria da Penha comentada em uma perspectiva jurídico-feminista. Rio de Janeiro: Lumen Juris, 2011. p. 289-305.

LAVIGNE, Rosane M. Reis. Caso Fonaje: o ativismo de juízes integrantes do Fórum Nacional dos Juizados Especiais - Fonaje no processo de elaboração da Lei Maria da Penha. In: CAMPOS, C. H. (Org.). Lei Maria da Penha comentada em uma perspectiva jurídicofeminista. Rio de Janeiro: Lumen Juris, 2011. p. 63-92.

MACHADO, Lia Zannota. Perspectivas em confronto: relações de gênero ou patriarcado contemporâneo? Brasília: Série Antropologia, 2000.

MATOS, Myllena C. CORTES, Iáris. O processo de criação, aprovação e implementação da Lei Maria da Penha. In: CAMPOS, C. H. (Org.). Lei Maria da Penha comentada em uma perspectiva jurídico-feminista. Rio de Janeiro: Lumen Juris, 2011. p. 39-63. 
PASINATO, Wania. Estudo de Caso sobre o Juizado de Violência Doméstica e Familiar e a Rede de Serviços de Cuiabá, Mato Grosso. Relatório Final. São Paulo, 2009. 103p.

PASINATO, Wania; GARCIA, I. J.; VINUTO, J.; SOARES, J. E. Medidas protetivas para mulheres em situação de violência. In: PARESCHI, A. C. C.; ENGEL, C. L.; BAPTISTA, G.C. (Org.). Direitos humanos, grupos vulneráveis e segurança pública. Brasília, DF: Ministério da Justiça, 2016. (Coleção Pensando a Segurança Pública, v. 6). p. 233-265.

PIMENTEL, Sílvia; PANDJIARJIAN, Valéria; BELLOQUE, Juliana. Legítima Defesa da Honra Ilegítima impunidade de assassinos um estudo crítico da legislação e jurisprudência da América Latina, 2006. Disponível em:

http://www.compromissoeatitude.org.br/wpcontent/uploads/2014/07/SILVIAPIMENTELetal _legitimadefesadahonra2006.pdf. Acesso em: 12 dez. 2018.

SCOTT, Joan. Gênero: uma categoria útil de análise histórica. Revista Educação e Realidade, Porto Alegre, 20, V.2, p. 71-99 jul./dez., 1995.

SILVA, Vanessa Ramos. DE CARLOS, Paula Pinhal. Violência de gênero e tribunal de justiça do Rio Grande do Sul: usos e percepções sobre gênero segundo o discurso dos desembargadores e das desembargadoras e reflexos na aplicação da Lei Maria da Penha. Revista de Estudos Empíricos em Direito, vol. 5, n. 1, mar. 2018, p. 49-66.

TRIBUNAL DE JUSTIÇA DO RIO DE JANEIRO. Comarca de São Gonçalo. Juízo da Vara de Violência Doméstica e Familiar contra a Mulher. Processo $n^{o}$ 0018790-25.2017.8.19.0004. Disponível em: https://www.conjur.com.br/dl/lei-maria-penha-tambem-protege-mulher.pdf. Acesso em: 11 fev. 2019.

TRIBUNAL DE JUSTIÇA DO RIO GRANDE DO SUL. Conflito de Jurisdição $n^{o}$ 70063555171. Terceira Câmara Criminal. Relator: Sérgio Miguel Achutti Blattes. Porto Alegre. Disponível em: www.tjrs.com.br. 2015a. Acesso em: 11 fev. 2019.

TRIBUNAL DE JUSTIÇA DO RIO GRANDE DO SUL. Conflito de Jurisdição $n^{o}$ 70066827734. Segunda Câmara Criminal. Relator: José Antônio Cidade Pitrez. Porto Alegre. Disponível em: www.tjrs.com.br. 2015b. Acesso em: 11 fev. 2019.

Submetido em: 02/04/2019

Aceito em: 07/05/2019 